\title{
Mobile Research Methods: Possibilities and Issues of a New Promising Way of Conducting Research
}

\author{
Robert Pinter ${ }^{\star}$, Daniele Toninelli ${ }^{\dagger}$ and \\ Pablo de Pedraza ${ }^{\ddagger}$ \\ *eNet, Hungary, robert.pinter@enet.hu, \\ $\dagger$ University of Bergamo, Italy, daniele.toninelli@unibg.it, \\ ¥University of Amsterdam, Netherlands, P.dePedraza@uva.nl
}

\begin{abstract}
This chapter introduces the WebDataNet group as the development framework of this book. It also presents the most relevant themes regarding the Mobile Research Methods in different research areas and the opportunities, issues and state of the art of mobile research. Finally, it summarizes the book structure and content.
\end{abstract}

\section{Keywords}

WebDataNet, mobile research, research methods, book introduction

\section{Background of the book: the scientific framework of WebDataNet \& the Task Force on Mobile Research}

Nowadays, in human daily activity, data are constantly flowing through cameras, via internet, satellites, radio frequencies, sensors, private appliances, cars, mobile phones, tablets and the like. Among all the tools currently used, mobile

\section{How to cite this book chapter:}

Pinter, R, Toninelli, D and de Pedraza, P. 2015. Mobile Research Methods: Possibilities and Issues of a New Promising Way of Conducting Research. In: Toninelli, D, Pinter, R \& de Pedraza, P (eds.) Mobile Research Methods: Opportunities and Challenges of Mobile Research Methodologies, Pp. 1-10. London: Ubiquity Press. DOI: http://dx.doi.org/10.5334/bar.a. License: CC-BY 4.0. 
devices (especially mobile phones, smartphones and tablets) are the most widespread, thanks also to their easier portability. People use them more and more often in all kind of areas of everyday life. Even in the developing world, more and more people conduct activities via the Internet. For instance, people use the Internet for shopping, reading newspapers, participating in forums, completing and making surveys, communicating with friends and making new ones, filing their tax returns, getting involved in politics, purchasing things or looking for information before purchasing offline. Mobile devices allow a wide range of heterogeneous activities and, as a result, they have great potential in terms of the different types of data that can be collected using them. In fact, the use of these devices as tools for data collection is gaining popularity. Mobile devices affect research as well, and the new situation provides, above all, an opportunity that applied research is only starting to explore. First, mobile usage already influences the applicability of traditional research methods. The representativeness of traditional landline samples is challenged by mobile-only respondents. Mobiles or tablets may be used in Computer-Assisted Personal Interviews (CAPI) instead of laptops. Respondents in online surveys planned for a PC environment may rather use mobile devices. Secondly, mobile devices can be used independently in mobile internet-based surveys, in mobile ethnography, in mobile diary, in location-based research or in passive measurement.

Aiming at exploring the many ways in which the Data Revolution ${ }^{1}$ could benefit social sciences methods, WebDataNet ${ }^{2}$ was created in 2009 by a small group of researchers willing to focus the discussion on web-based data collection methods. Thanks to the support of the European Union programme for the Coordination of Science and Technology (COST), ${ }^{3}$ WebDataNet has become an ever-growing, unique, multidisciplinary network that has brought together leading web-based data collection experts from several institutions, disciplines, and relevant backgrounds from more than 35 different countries (Steinmetz et al. 2012; Steinmetz et al. 2014; WebDataNet 2010).

The fundamental goal of WebDataNet is to address the methodological issues of web-based data collection and to foster its scientific usage. In order to fulfil this goal WebDatNet's scientific structure is designed to follow a bottom-up approach. The framework consists of three general Working Groups (WGs): WG1 - Quality issues, WG2 - Innovation and WG3 - Implementation. Researchers can organize their Task Forces (TFs) within these WGs to foster their research interest by building collaborations and synergies with other

\footnotetext{
${ }^{1}$ Data emerging from all activities developed by means of mobile devices, together with an increase and proliferation of digital storage capacity, have activated discussion about concepts such as Big Data (Couper 2013; Mayer-Schonberger \& Cukier 2013; Snijders, Matzat \& Reips 2012), Organic Data (Groves 2011), the Data Revolution (United Nations 2013) or the Digital data tsunami (Prewitt 2013).

${ }^{2}$ For more information on WebDataNet, see www.webdatanet.eu.

${ }^{3}$ For more information on COST, see www.cost.eu.
} 
researchers. ${ }^{4}$ WebDataNet has supported more than 30 TFs within the topic of web-based data collection methods and implementations by organizing meetings, workshops, training schools and supporting short-term scientific research visits. This book was written mainly thanks to the collaborations activated in the framework of the WebDataNet's Task Force \# 19 (TF19). This Task Force focuses on mobile research and is coordinated by Robert Pinter. It was founded in Mannheim, in March 2013, by a group of researchers interested in the topic. TF19's fundamental goal has been to systematically compare mobile research to traditional methods and to investigate it as an independent research method.

The task force on mobile research was also the main actor in one of the WebDataNet meetings, organized in Larnaca (Cyprus) in April 2014..$^{5}$ A conference on Mobile Research took place in Larnaca, involving many members of the TF19. The potential of a clearly crucial topic, the major role that mobile devices could play in the future of research and the determination of TF19 members gave rise to the idea of developing a book on mobile research. This book includes works that are a further development of preliminary presentations made in the Larnaca Conference, but it also collects works that discuss results of new research activities.

\section{Book target and contribution to the field: the importance of mobile research}

This book, Mobile Research Methods, is focusing on the study of the use of mobile devices in various research contexts. The impact of mobile devices in research is a relatively recent and still partly unexplored topic. This book mainly aims at deeply studying this topic and at providing readers with a more detailed and updated knowledge, compared to what is currently available in the literature. This is done considering different aspects: main methodological possibilities and issues, comparison and integration with more traditional survey modes or ways of participating in research, quality of collected data, main characteristics of the new kind of respondents (unintended mobile respondents), use of mobile in commercial market research, study of the representativeness of studies based only on the mobile-population, analysis of the current spread of mobile devices in several countries, and so on. Thus, the book also provides the readers with interesting research findings that include a wide range of countries and contexts.

Many books have already been published about mobile research in the last few years, for example: Maxl, Döring \& Wallisch 2009; Häder, Häder \& Kühne 2012; Poynter, Williams \& York 2014; Appleton 2014. However, our book,

\footnotetext{
${ }^{4}$ For more information on the scientific framework of WebDataNet, see: http://webdatanet.cbs. $\mathrm{dk} /$ index.php/test/scientific-coordination.

${ }^{5}$ http://webdatanet.cbs.dk/index.php/data/117-next-mc-meeting-cyprus-2014.
} 
Mobile Research Methods, is more general than Appleton's one, more up to date than Maxl, Döring and Wallisch's book, oriented to a wider audience than Poynter, Williams and York's book and broader than Häder, Häder and Kühne's book, which focuses more on traditional landline phone surveys. This book is different thanks to the fact that its development involved the multinational and inter-disciplinary team of WebDataNet, with team members from different research fields, such as social sciences, survey methodology, applied statistics, and marketing and behavioral sciences (Steinmetz et al. 2014).

The mobile research phenomenon is still mostly unexplored, considering its recent worldwide spreading, and it involves several research disciplines: thus, a more complete, more in-depth and more updated study of the phenomenon is needed that considers a variety of points of view and approaches. New methodological questions arise with mobile phone research, and we need to explore these main research questions. For example, what is the relation between mobile mode and other, more traditional methods? What are the advantages and disadvantages of mobile data collection? What is the reliability and validity of research data collected by means of mobile phones? What is the quality of mobile-gathered data? How does mobile research affect coverage issues and nonresponse bias and what is the difference between mobile and non-mobile respondents? This book is most useful for those readers who are interested in online research methods, especially in online panel research. It can be also interesting for readers who plan to use mobile device applications for research purposes.

The potential readership of Mobile Research Methods includes: researchers and practitioners; users of web panel data and of telephone surveys data; survey methodologists and web and mobile survey designers; market research professionals; policy-makers, researchers and practitioners working on poverty measurement and survey data innovations; and survey methodology students and advanced research courses' students (e.g. advanced university courses, $\mathrm{PhD}$, master or specialized courses). This book can also be helpful to research and data collection companies, online panel providers and other research institutions (in private or public sector). Hence this book is not only a teaching material, it can also be valuable for public or private research institutions that are involved in the development of any kind of research.

\section{Structure of the book}

This book has three sections. The first part includes an introduction to the use of mobile devices in research and to its main potentialities (e.g. the integration with more traditional survey modes) and issues. The second part mainly focuses on the quality of data collected by means of mobile devices, also making a comparison with other survey modes. The third part studies mobile web survey participation, analyzing the spread of mobile devices in different countries 
and the willingness of participating in surveys by means of these devices; it also proposes new methods of data collection based on smartphone applications.

The first part of the book starts with the chapter entitled 'The Utilization of Mobile Technology and Approaches in Commercial Market Research'. In this chapter, Ray Poynter underlines the importance of mobile technology, introducing its main uses in various research contexts, together with the current most common approaches. For example, Poynter classifies research projects according to the use of mobile devices. Introducing mobile technology, the author makes a comparison with an iceberg ('the less visible is much larger than the visible'). By means of this comparison, he explains how the projects in which mobile devices are used represent only a small fraction of the role that mobile research has been playing in the last few years. The author's approach focuses, in particular, on commercial research, also digging out the main issues involved in the use of mobile technology.

Even if the mobile technologies are more and more frequently used in research, the mobile research methods still have to be fully explored and studied. Several new emerging quality issues are causing concerns, and a lot of research projects have started to study the quality of data collected using mobile devices. One of these projects, aimed at dealing with some of these challenges, is the LAC (Listening to Latin America and the Caribbean) project. The project is described in the chapter written by Amparo Ballivian, João Pedro Azevedo and Will Durbin ('Using Mobile Phones for High-Frequency Data Collection'). The main objective of the study is to test the reliability and validity of survey data collected by means of mobile phones, focusing on CATI surveys. In this framework, the research team reached important empirical results. The authors are now able to provide readers with open-source materials ('data, reports, guidelines, software, user manuals, video and other materials') that can be extremely useful to both plan and manage mobile surveys (and, in particular, mobile phone surveys). In this chapter, the authors also underline the main advantages of mobile technology together with its main issues.

It is clear that when a new research methodology arises, new issues emerge at the same time. First of all it is necessary to understand if and how the new methodology can be successfully integrated with other more traditional data collection methods. From this perspective, the spread of mobile devices can be seen, for example, as an effective help in compensating for the drop of coverage rates in landline telephone surveys. Nevertheless, the inclusion of mobile phone participation causes new arising issues, or confirms issues commonly found with other more traditional data collection methods. In the chapter entitled 'An Overview of Mobile CATI Issues in Europe', Ana Slavec and Daniele Toninelli study the mobile-CATI fieldwork, summarizing and reviewing some of the main challenges that mobile phone usage causes to survey participation. The authors mainly focus on issues linked to legal and ethical rules, to the coverage of the target population, to the sample selection or to the main sources of error (nonresponse, measurement) and introduce 
the readers to some adjustment procedures. The depicted situation is strongly varying according to the national/regional contexts and legislations. Nevertheless, some general rules and recommendations can be identified and can be followed in planning and conducting research, in order to at least reduce the impact of the different issues on the quality of collected data.

On the one hand, the integration of mobile participation in other more traditional survey modes can help reduce or compensate for arising issues. On the other hand it also becomes necessary to make a comparison between data collected by means of the new technologies and data collected using more traditional research methods. Within this perspective, the second part of the book is mainly focused on the study of the quality of collected data. Are the new methods more effective, fast, precise, etc.? How much can be gained from using mobile methods in research? Is mobile data collection more competitive? Can it help in obtaining data of higher quality? Ioannis Andreadis, in the chapter entitled 'Comparison of Response Times between Desktop and Smartphone Users', focuses on the completion time in the framework of web surveys. The main objective, considering both the item response times and the total response times, is to test if both types of response times can be substantially reduced using mobile methods of data collection (smartphones, in this case), in comparison to a more traditional fixed-PC survey participation.

The quality of data collected using mobile devices in the context of web surveys is also the central topic of the chapter written by Aigul Mavletova and Mick Couper, 'A Meta-Analysis of Breakoff Rates in Mobile Web Surveys'. The starting point is a meta-analysis based on several studies done on both probability-based and non-probability-based panels. In particular, the authors study the breakoff rates obtained in mobile web surveys subject to various experimental settings. Among other factors, they also take into account the optimization of the survey for mobile participation. The authors' findings also provide readers with some suggestions about the setting of web surveys that can help in reducing the breakoff rates.

The quality of data collected using mobile devices is also strictly linked to the characteristics of the population that can be potentially involved in a research/ survey project. This is the focus point of the third part of the book. According to some preliminary studies (e.g. Fuchs \& Busse 2009), there are characteristics differentiating the population owning a mobile device (the so-called 'mobile early adopters'). But these differences, despite being confirmed by more recent studies (e.g. de Bruijne \& Wijnant 2014), are becoming more and more narrow, thanks to the quick spread of mobile devices among the general population. Nevertheless, at this point, it is not clear whether there are big differences between people that have access to mobile web and people that are mostly fixed-PC or laptop web users. Moreover, the situation is evolving very quickly. Thus, further updated studies are needed. In these circumstances, the following three chapters focus on the study of the population involved in using mobile devices in research or survey projects. 
The first of the three chapters ('Who Are the Internet Users, Mobile Internet Users, and Mobile-mostly Internet Users?: Demographic Differences across Internet-use Subgroups in the U.S.', by Christopher Antoun) analyzes the characteristics of some specific groups of respondents by means of data coming from a Pew telephone survey. The study starts from the premise that the quality of collected data can be affected by allowing or not allowing a potential respondent to participate to a survey using a mobile device, on one hand, and by the potential respondent's decision to participate or not by means of a specific device, on the other hand. In Antoun's chapter some of the main characteristics (both demographic and non-demographic) of different subgroups of respondents are studied. These groups are defined considering: the use of Internet, the mobile web use (conditional on the Internet use) and the prevailing mobile vs fixed-PC usage (conditional to the mobile web use). The author's approach is helpful in defining possible coverage issues and in detecting if and how the mobile respondents can differ from non-mobile respondents.

Furthermore, as also underlined in the previous chapters, when a mobile survey is planned there are two relevant points that have to be taken into consideration: the availability of mobile devices among the units of the target population and the willingness of respondents to participate by means of these devices.

The chapter written by Melanie Revilla, Daniele Toninelli, Carlos Ochoa and Germán Loewe, entitled 'Who Has Access to Mobile Devices in an Online Opt-in Panel? An Analysis of Potential Respondents for Mobile Surveys', mainly deals with the first of these two points. This study is based on data collected by a non-probability-based panel. The coverage level of mobile devices (mainly smartphones and tablets) considering both the devices owned by potential respondents and the devices that they have at their disposal (even if notowned) is explored in several countries. It is clear that the increasing spread of the mobile devices availability directly affects the quality of collected data and the representativeness of the surveyed population. This chapter highlights that there is often more than one device at the respondents' disposal. Thus, the necessity to study a) what pushes respondents to choose a certain device for the survey participation (their preferences) and b) the characteristics of the respondents that own a certain kind of device (or a combination of them) clearly emerges.

Regarding the preferences of respondents, an interesting analysis is presented by Robert Pinter in his chapter: 'Willingness of Online Access Panel Members to Participate in Smartphone Application-Based Research'. Given the quickly spreading penetration of mobile devices, the author studies the use of smartphone applications in research. The use of downloaded or pre-installed smartphone applications is an additional and new emerging way of conducting online research. It represents our 'look to the future', considering that it is not currently as well developed and well spread as the more traditional mobile web survey participation. Moreover, this new methodology includes an offline participation option (responses are only synchronized if internet access is available). Thus, it requires a further and more specifically developed study of 
the population that can be potentially involved in terms of both its characteristics and its members' willingness to participate in application-based research of different kinds. This last chapter and its findings provides further details about one of the potentially most interesting evolutions of research conducted by means of mobile devices in the future.

\section{Acknowledgements}

Editors and authors would like to acknowledge the contribution of the COST Action IS1004: the networking activities that the project were able to start and stimulate made possible the realization of this book. The author would also like to acknowledge WebDataNet, the European network for web-based data collection (COST Action IS1004, http://webdatanet.cbs.dk/), for giving birth to our collaboration and for funding the publication of this book. Moreover, we would like to thank Christopher Antoun, Aigul Mavletova, Melanie Revilla and Ana Slavec for contributing to the development of this chapter.

\section{References}

Appleton, E. (2014). In the Moment. Perspectives on Mobile Market Research. Edward Appleton.

Couper, M. P. (2013). Is the sky falling? New technology, changing media, and the future of surveys. Survey Research Methods, 7(3), 145-156.

de Bruijne, M., \& Wijnant, A. (2014). Mobile Response in Web Panels, Social Science Computer Review, 32(6), 728-742. DOI: http://dx.doi. org/10.1177/0894439314525918

Fuchs, M., \& Busse, B. (2009). The coverage bias of mobile web surveys across European countries. International Journal of Internet Science, 4, 21-33.

Groves, R. (2011). Three eras of survey research. Public Opinion Quarterly, 75(5), 861-871. DOI: http://dx.doi.org/10.1093/poq/nfr057

Häder, S., Häder, M., \& Kühne, M. (2012). Telephone Surveys in Europe. Springer. DOI: http://dx.doi.org/10.1007/978-3-642-25411-6

Maxl, E., Döring, N., \& Wallisch, A. (2009). Mobile Market Research. Herbert Von Halem Verlag.

Mayer-Schonberger, V., \& Cukier, K. (2013). Big data A Revolution That Will Transform How we Live, Work and Think. Boston, New York: An Eamon Dolan Book, Houghton Mifflin Harcourt.

Poynter, R., Williams, N., \& York, S. (2014). The Handbook of Mobile Market Research: Tools and Techniques for Market Researchers. John Wiley \& Sons Ltd. 
Prewitt, K. (2013). The 2012 Morris Hansen lecture: Thank you Morris, et al., for Westat, et al. Journal of Official Statistics, 29(2), 223-231. DOI: http:// dx.doi.org/10.2478/jos-2013-0018

Snijders, C., Matzat, U., \& Reips, U.-D. (2012). 'Big Data': Big gaps of knowledge in the field of Internet science. International Journal of Internet Science, $7,1-5$.

Steinmetz, S., Kaczmirek, L., De Pedraza, P., Reips, U.-D., Tijdens, K., Lozar Manfreda, K., Rowland, L., Serrano, F., Vidakovic, M., Vogel, C., Belchior, A., Berzelak, J., Biffignandi, S., Birgegard, A., Cachia, E., Callegaro, M., Camilleri, P. J., Campagnolo, G. M., Cantijoch, M., Cheikhrouhou, N., Constantin, D., Dar, R., David, S., De Leeuw, E., Doron, G., Fernandez-Macias, E., Finnemann, N. O., Foulonneau, M., Fornara, N., Fuchs, M., Funke, F., Gibson, R., Grceva, S., Haraldsen, G., Jonsdottir, G., Kahanec, M., Kissau, K., Kolsrud, K., Lenzner, T., Lesnard, L., Margetts, H., Markov, Y., Milas, G., Mlacic, B., Moga, L. M., Neculita, M., Popescu, A. I., Ronkainen, S., Scherpenzeel, A., Selkala, A., Kalgraff Skjak, K., Slavec, A., Staehli, M. E., Thorsdottir, F., Toninelli, D., Vatrapu, R., Vehovar, V., Villacampa Gonzalez, A., Winer, B. (2012). WEBDATANET. A web-based data collection, methodological challenges, solutions and implementations. International Journal of Internet Science, 7(1), 78-89. Retrieved from http://www.ijis.net/ijis7_1/ ijis7_1_supplement_pre.html.

Steinmetz, S., Slavec, A., Tijdens, K., Reips, U.-D., de Pedraza, P., Popescu, A., Belchior, A., Birgegard, A., Bianchi, A., Ayalon, A., Selkala, A., Villacampa,A., WinerB.(D.), Mlacic,B., Vogel,C., Gravem,D.,Avello,D.G., Constantin, D., Toninelli, D., Troitino, D., Horvath, D., De Leeuw, E., Oren, E., Fernandez-Macias, E., Thorsdottir, F., Ortega, F., Funke, F., Campagnolo, G. M., Milas, G., Grünwald, C., Jonsdottir, G., Haraldsen, G., Doron, G., Margetts, H., Miklousic, I., Andreadis, I., Berzelak, J., Angelovska, J., Schrittwieser, K., Kissau, K., Manfreda, K. L., Kolsrud, K., Skjak, K. K., Tsagarakis, K., Kaczmirek, L., Lesnard, L., Moga, L. M., Teixeira, L. L., Plate, M., Kozak, M., Fuchs, M., Callegaro, M., Cantijoch. M., Kahanec, M., Stopa, M., Staehli, E. M., Neculita, M., Ivanovic, M., Foulonneau, M., Cheikhrouhou, N., Fornara, N., Finnemann, N. O., Zajc, N., Nyirő, N., Louca, P., Osse, P., Mavrikiou, P., Gibson, R., Vatrapu, R., Dar, R., Pinter, R., Torres, R. M., Douhou, S., Biffignandi, S., Grceva, S., David S., Ronkainen, S., Csordas, T., Lenzner, T., Vesteinsdottir, V., Vehovar, V., \& Markov, Y. (2014). WEBDATANET: Innovation and Quality in Web-Based Data Collection. International Journal of Internet Science, 9(1). Retrieved from http://www.ijis.net/ ijis9_1/ijis9_1_supplement_pre.html.

United Nations. (2013). A New Global Partnership: Eradicate poverty and transform economies through sustainable development. The Report of the 
High-Level Panel of Eminent Persons on the Post-2015 Development Agenda. Retrieved from http://www.un.org/sg/management/pdf/HLP_ P2015_Report.pdf

WebDataNet. (2010). Memorandum of Understanding for the implementation of a European Concerted Research Action designated as COST Action IS1004: WEBDATANET: web based data-collection - methodological challenges, solutions and implementations. Retrieved from http://webdatanet.cbs.dk/ images/presentations/mou\%20is1004-webdatanet.pdf 